\title{
$\angle$ Research Square \\ Characterization of a case series of Mastocytosis in a health care center in Cali, Colombia
}

\section{Daniela Marulanda Sandoval}

Universidad Libre Cali https://orcid.org/0000-0001-7135-3864

Oscar Felipe Borja Montes ( $\nabla$ oscarfborja@hotmail.com )

Universidad Libre Cali https://orcid.org/0000-0003-3569-9360

Jose Leonel Zambrano Urbano

Universidad Libre Cali https://orcid.org/0000-0002-4959-9136

Rigoberto Gomez Gutierrez

Hematonncólogos de Occidente SA

\section{Case Report}

Keywords: Cutaneous Mastocytosis, Systemic Mastocytosis, Eosinophilia, Treatment, Tryptase

Posted Date: September 27th, 2021

DOl: https://doi.org/10.21203/rs.3.rs-939459/v1

License: (a) This work is licensed under a Creative Commons Attribution 4.0 International License. Read Full License 


\section{Abstract}

Mastocytosis is a group of rare diseases, which correspond to neoplasms of the myeloid lineage. In Colombia there are only case reports and so far there are no studies of greater extension. We conducted a case series in which an active search was made for patients with a diagnosis of mastocytosis, either cutaneous (CM) or systemic (SM), from the total number of consultations between June 2004 and June 2019 in the reference hemato-oncologic center ("mastocytosis"). A total of 4 cases of CM and 3 cases of SM were identified. The most frequent clinical manifestations were skin lesions, which were present in $100 \%$ of patients; of these hyperpigmented macules were the most frequent findings. Serum tryptase (TS) levels were found to be elevated in $67 \%(2 / 3)$ of patients with DM. Both TS levels and mean absolute eosinophils were higher in patients with MS. In this case series we found a higher frequency of extracutaneous involvement, and in general a very poor response to the management. The findings of this series are comparable to those reported in world literature.

\section{Introduction}

Mastocytosis is a group of diseases, which correspond to neoplasms of the myeloid lineage. They are characterized by the increase and pathological accumulation of mast cells in one or several organs, most frequently involving the skin, bone marrow, liver and gastrointestinal tract ${ }^{12}$. They cover a wide clinical spectrum that may vary according to the age group in which they occur. In adults, the systemic variant is most frequently observed, characterized by involvement of the bone marrow and extracutaneous tissues, with a tendency to present with persistent courses ${ }^{3}$. The clinical manifestations derive from the products secreted by mast cells and their infiltration in the different organs and tissues ${ }^{1}$.

Mastocytosis can be divided into variants of cutaneous mastocytosis (CM), systemic mastocytosis (SM) and localized mast cell tumors ${ }^{5}$. CM is defined by the presence of one or more cutaneous lesions limited to the skin. It is subdivided into maculopapular or urticaria pigmentosa (MPCM), diffuse cutaneous (DCM) and localized cutaneous mastocytoma. The maculopapular variant is the most common ${ }^{3} 56$.

SM is defined when the involvement of any extracutaneous tissue is histologically demonstrated, showing multifocal or diffuse infiltration of the organ. An annual incidence of SM is reported to be 0.89 cases per 100,000 population ${ }^{9}$. Most patients with SM present with the subtype of Indolent Systemic Mastocytosis (ISM), which accounts for $84 \%$ of all cases of SM in some European case series ${ }^{9}$. The presence of an activating mutation in the c-KIT gene (most commonly D816V mutation) has been described in more than $90 \%$ of the population with $\mathrm{SM}^{78}$.

Mastocytosis is considered an extremely rare disease 4 . A study conducted in Denmark reports an annual incidence of 0.89 cases per 100,000 population for systemic mastocytosis, finding that $82 \%$ of cases corresponded to the ISM variant ${ }^{9} 1011$. In general, there is limited data to describe the occurrence of this entity, which is believed to be partly due to the recent consensus of its diagnostic criteria in 2001 and the difficulty in developing robust epidemiological studies. In Latin America there is little literature evidencing the prevalence and incidence of this disease. There are some reports from some case series describing both SM and CM, mostly reported in countries such as Mexico, Ecuador and Argentina ${ }^{13141516}$. In Colombia there are few articles reporting isolated cases ${ }^{17}$, and so far no case series have been reported. 
At present, there is limited consensus on therapeutic algorithms, and there is a lack of data on experimental studies that are still in progress ${ }^{10} 1112$.

The following is a clinical case series of 7 patients with mastocytosis in a medical center in the city of Cali, Colombia. Clinical variables, frequency and severity of symptoms, paraclinical and therapeutic variables are described.

\section{Materials And Methods}

Descriptive case series study in which an active search was performed for patients with a diagnosis of either cutaneous or systemic mastocytosis from the total number of consultations between June 2004 and June 2019 in the reference hemato-oncology center ("mastocytosis"). A total of 7 patients were found, their informed consent was obtained according to the guidelines of the local ethics committee and the Helsinki Act. Compliance with diagnostic criteria was verified according to the existing WHO guidelines. The different sociodemographic, clinical, paraclinical and treatment response variables were characterized according to clinical history data. Qualitative variables were analyzed by frequencies and proportions, quantitative variables were measured by frequencies, averages and ranges.

\section{Results}

The case series studied, included 7 patients, (See Table 1), between 27-69 years old, of which 71\% were female (See graphs 1 and 2). Fifty-seven percent of the patients were diagnosed with CM and $43 \%$ with SM. Of the patients with SM, 100\% were female, and of the patients with CM there were no differences in sex.

The diagnostic method used in all cases was histopathological, 57\% underwent skin biopsy, which confirmed the diagnosis of $\mathrm{CM}$, and $43 \%$ underwent bone marrow biopsy, confirming the diagnosis of SM.

Skin lesions were the most frequent manifestations found in this series, presented in $100 \%$ of the patients (see Table 1), with hyperpigmented macular lesions being the most frequent.

Pruritus was present in $57 \%$ of all patients. It was prevalent in $75 \%$ of patients with $\mathrm{CM}$, and in $33 \%$ of patients with SM.

Diarrhea was present in $25 \%$ of patients with CM and in $67 \%$ of patients with SM. Headache occurred in $25 \%$ of patients with $\mathrm{CM}$ and in $33 \%$ of patients with SM. Insomnia was prevalent in $33 \%$ of patients with SM. Epistaxis was present in $25 \%$ of patients with CM. Abdominal pain occurred in $25 \%$ of patients with CM. (See graph 3 )

As for the physical examination findings, skin lesions were found in $100 \%$ of patients with CM and SM, Darier's sign was observed in only $14 \%$ of the total patients. (See Table 1 )

Serum tryptase levels were found to be elevated ( $\geq 20 \mathrm{ng} / \mathrm{mL}$ ) in $67 \%$ of patients with SM, showing a higher mean tryptase in patients with SM $(59.7 \mathrm{ng} / \mathrm{mL}, 95 \% \mathrm{Cl}: 14.9-141)$, compared to patients with $\mathrm{CM}(6.5 \mathrm{ng} / \mathrm{mL}$, $95 \%$ Cl: 2.5-15.1). (See graph 4) Of the total number of patients with SM, 100\% presented eosinophilia compared to $25 \%$ of patients with CM. Patients with SM had a higher mean absolute eosinophil count (2196, 95\% Cl: $990-4440)$ than patients with $\mathrm{CM}(300,95 \% \mathrm{Cl}$ : 130-720). As for cytogenetic studies, C-KIT mutation 
positivity was reported in $25 \%$ of patients with CM, while none of the patients with SM had the C-KIT mutation. (See Table 1).

Regarding treatment, antihistamines were used in $86 \%$ of the total patients. Prescribed in $75 \%$ of patients with CM and in $100 \%$ of patients with SM. Response to treatment in these patients was evidenced in $25 \%$ of the total patients. Ranitidine was used by $25 \%$ of patients with CM, Montelukast was prescribed in $33 \%$ of patients with SM, medications such as montelukast and ranitidine were prescribed, however $100 \%$ of patients persisted with symptomatology. Topical corticosteroids were prescribed in $43 \%$ of the total patients, used in $50 \%$ of patients with $\mathrm{CM}$ and in $33 \%$ of patients with SM, with complete resolution of symptomatology in only $14 \%$ of the patients in the series. Cytoreductive biologic drugs, such as imatinib, were only used in 1(14\%) patient of the total series studied, however in this patient there was no complete resolution of the symptomatology. (See graph 5)

The response to treatment showed complete resolution of symptoms in $25 \%$ of the total number of patients treated with antihistamines. Patients treated with montelukast reported $100 \%$ persistence of symptoms. Ranitidine provided resolution in $100 \%$ of patients. Topical corticosteroids provided complete resolution in $25 \%$ of patients.

Imatinib did not provide complete resolution of symptoms. (See graph 6)

In this series, complete resolution of symptoms was only evidenced in $25 \%$ of the patients who received antihistamines or topical corticosteroids, and no superior impact was observed with the rest of the therapies used as second and third line.

\section{Discussion}

Mastocytosis constitute a group of very low frequency diseases characterized by pathological accumulation of mast cells in different organs or tissues ${ }^{1}$. They are considered underdiagnosed diseases with an important impact on patient morbidity ${ }^{12}$. The recent consensus on diagnostic criteria and the clinical difficulties in suspecting this entity have limited its description and contribute to the current lack of knowledge of this pathology ${ }^{10}$. This article reports a case series on mastocytosis in adults in Colombia, so far the largest series reported in the region, which mainly showed that there was complete resolution of symptoms in only $25 \%$ of patients who received antihistamines or topical corticosteroids, and with little response to the rest of the therapies used. This indicates that it is a difficult pathology to treat.

In this series of patients with mastocytosis, the majority were women and specifically in SM, where $100 \%$ corresponded to the female sex. This finding is in accordance with the Vikse series in which $85.7 \%$ belonged to this gender and of these, $100 \%$ had SM ${ }^{18}$. Although there are no data that imply a greater association between mastocytosis in women than in men, a correlation has been reported between elevated estrogen levels and greater severity of the symptoms (especially during pregnancy, representing $30 \%$ of severe cases). ${ }^{19}$

Skin manifestations were the most common symptomatology in $100 \%$ of patients. Despite the heterogeneity that typically characterizes skin lesions in this entity, it was observed that hyperpigmented, monomorphic maculopapular lesions were the most common. This finding is in agreement with that reported in the literature, 
where Hartmann $\mathrm{K}$, et al, found a higher frequency of presentation of this type of lesions. In this study it was observed that $80 \%$ of all patients with mastocytosis presented cutaneous lesions, with urticaria pigmentosa ${ }^{12}$ 20

Pruritus was one of the most frequent clinical symptoms in more than $50 \%$ of patients, predominantly in patients with $\mathrm{CM}$, a finding that is consistent with Vikse's case series, where it was present in $100 \%$ of patients 21. In contrast, gastrointestinal symptoms such as diarrhea were present in only $28 \%(2 / 7)$ of the total series, which corresponded to patients with SM. Bhullar, et al, in their case series of 107 patients, described diarrhea in $68 \%$ of patients with $\mathrm{SM}$, but also in $44 \%$ of those with $\mathrm{CM}^{22}$, the latter finding may differ from the result of this series due to the unequal sample sizes of the two studies. Most case series describe that gastrointestinal symptoms are predominant in patients with SM, reaching a prevalence of up to $70 \% 18$. Other systemic symptoms such as headache, insomnia, abdominal pain, were reported in only $14 \%$ of this series.

Regarding laboratory variables in this study, serum tryptase levels were found to be elevated $(\geq 20 \mathrm{ng} / \mathrm{mL})$ in $67 \%$ of patients with SM, with a higher mean tryptase in patients with SM $(59.7 \mathrm{ng} / \mathrm{mL}, 95 \% \mathrm{Cl}: 14.9-141)$, compared to patients with $\mathrm{CM}(6.5 \mathrm{ng} / \mathrm{mL}, 95 \% \mathrm{Cl}: 2.5-15.1)$. This finding was corroborated by a study in Austria of 59 patients, where $81 \%$ of those with SM had levels above $20 \mathrm{ng} / \mathrm{mL}$, compared to $13 \%$ of patients with $\mathrm{CM}^{25}$. In Lange's case series, tryptase levels were found to be elevated in 6 patients out of 10 with $\mathrm{CM}$, a finding different from what was found in this series, in which none of the patients with $\mathrm{CM}$ had tryptase levels above $20 \mathrm{ng} / \mathrm{mL}$. Additionally, a relationship between decreasing tryptase levels and improvement of clinical manifestations has been found in the literature ${ }^{26}$, however in this study, clinical manifestations were not followed up according to tryptase levels. Serum tryptase levels are a useful tool for the follow-up of patients with mastocytosis and have been related to the course of the disease, so it is considered an important prognostic marker for the severity of clinical manifestations ${ }^{23} 24$.

It has been observed that eosinophilia, universally considered as equal to or greater than 450 eosinophils/ $\mu \mathrm{L} 27$, is an important parameter that can have an important prognostic value ${ }^{82}$. In this case series, $100 \%$ of patients with SM presented eosinophilia, contrasting with $25 \%$ of all patients with CM. A relevant finding is that patients with SM had a higher mean absolute eosinophil count (2196, 95\% Cl: 990-4440) than patients with CM (300, 95\% Cl: 130-720).

Eosinophilia has been most frequently associated with SM in the literature ${ }^{5}$. In a case series of 123 patients with SM, a prevalence of eosinophilia was observed in $34 \%$ of patients, predominantly found in patients with $\mathrm{SM}$ associated with myeloproliferative neoplasm ${ }^{28}$. Other studies have referred to the prognostic value of eosinophilia with respect to the severity of clinical manifestations in SM, and additionally, a correlation has been found between the average number of eosinophils and the average survival, defining that the most favorable average survival is found in patients with SM with mild eosinophilia 828 .

It is pertinent to highlight that there is an important association between $\mathrm{CM}$ and the presence of gain-offunction KIT mutations in approximately 60 to $80 \%$ of cases $^{18}$. In this study, C-KIT mutation positivity was detected in $25 \%(1 / 4)$ of cases with $\mathrm{CM}$. 
Regarding the therapeutic approach, symptomatic treatment was given in the majority of patients with CM and $\mathrm{SM}$, without distinguishing between the variants. The mainstay of therapy in all symptomatic patients involves the combination of histamine receptor antagonists HR1 and HR2 ${ }^{2}{ }^{29}$. In this study the response to treatment showed complete resolution of symptoms in $25 \%$ of all patients managed with antihistamines. This shows a poor response to the current available therapy. Some management guidelines recommend directing therapy depending on the variant of mastocytosis. As an example of the above for urticaria pigmentosa, CM subtype, it is recommended to initiate a dose four times higher than the conventional dose of antihistamines ${ }^{30}$.

In cases where symptoms persist, the recommendation is the addition of $\mathrm{H} 2$ antihistamines and leukotriene antagonists $^{30}$. Although most patients in this series received second-line medications, symptoms persistence was evident in $100 \%$ of patients receiving montelukast. Only ranitidine, a histamine $\mathrm{H} 2$-receptor antagonist, achieved complete resolution in $100 \%$ of the patients who received it as a second-line drug. This finding is comparable to those found in other case series of similar size, ${ }^{31}$ at present there are limitations to symptomatic management. Therapeutic efforts are focused on identifying new potential targets, and on knowing the range of different doses with current treatments ${ }^{12}$. As an example of this, an in vitro study with terfenadine and loratadine achieved the suppression of spontaneous growth of CM cell lines ${ }^{32}$; however, these are in vitro findings that have not been demonstrated in vivo.

In this series it was observed that one patient with SM was refractory to first and second line antihistamine management. Therefore, he was treated with a tyrosine kinase inhibitor, such as imatinib, without symptom resolution. It has been demonstrated that the presence of the KIT D816V mutation confers resistance to therapy with imatinib, mastinib and other therapies that have KIT as a therapeutic $\operatorname{target}^{73}$. Resistance to treatment with imatinib in patients with SM has been frequently reported in the literature ${ }^{30}$. However, the existence of other mutations in different genes has also been suggested. Rearrangements in the platelet-derived growth factor (PDGF) gene, has also been associated with resistance to therapy. Other studies mention that the inadequate use of sequencing methods for the D816V KIT mutation can account for a significant number of false negatives ${ }^{34}$.

\section{Conclusion}

Mastocytosis in all its presentations is a rare disease, with little evidence to guide its diagnosis and management. In this case series we found a higher frequency of extracutaneous involvement, elevated levels of ST and eosinophils in patients with SM and in general a very poor response to management. The findings of this series are comparable to those reported in the world literature.

\section{Declarations}

\section{CONFLICT OF INTEREST STATEMENT:}

Nothing to declare.

\section{STATEMENT OF SUBMISSION TO THE ETHICS COMMITTEE}

It is certified that the work was approved by the ethics committee of the hemato-oncology center of reference. 


\section{References}

1. Akin C, Valent P. Diagnostic criteria and classification of mastocytosis in 2014. Immunol Allergy Clin North Am. 2014;34(2):207-218. doi:10.1016/j.iac.2014.02.003

2. Arock M, Valent P. Pathogenesis, classification and treatment of mastocytosis: State of the art in 2010 and future perspectives. Expert Rev Hematol. 2010;3(4):497-516. doi:10.1586/ehm.10.42

3. Chisholm KM. Cutaneous mastocytosis. Int Arch Allergy Immunol. 2002;127(2):143-146. doi:10.4267/2042/70659

4. Valent $P$, Horny HP, Escribano $L$, et al. Diagnostic criteria and classification of mastocytosis: A consensus proposal. Leuk Res. 2001;25(7):603-625. doi:10.1016/S0145-2126(01)00038-8

5. Valent P, Akin C, Metcalfe DD. Mastocytosis: 2016 updated WHO classification and novel emerging treatment concepts. Blood. 2017;129(11):1420-1427. doi:10.1182/blood-2016-09-731893

6. Hannaford R, Rogers M. Presentation of cutaneous mastocytosis in 173 children. Australas J Dermatol. 2001;42(1):15-21. doi:10.1046/j.1440-0960.2001.00466.x

7. Arock M, Sotlar K, Akin C, et al. KIT mutation analysis in mast cell neoplasms: Recommendations of the European Competence Network on Mastocytosis. Leukemia. 2015;29(6):1223-1232. doi:10.1038/leu.2015.24

8. Kluin-Nelemans HC, Reiter A, Illerhaus A, et al. Prognostic impact of eosinophils in mastocytosis: analysis of 2350 patients collected in the ECNM Registry. Springer Nat. 2019;34(4):1090-1101. doi:10.1038/s41375-019-0632-4

9. Cohen SS, Skovbo S, Vestergaard H, et al. Epidemiology of systemic mastocytosis in Denmark. $\mathrm{Br} \mathrm{J}$ Haematol. 2014;166(4):521-528. doi:10.1111/bjh.12916

10. Horny HP, Sotlar K, Valent P, Hartmann K. Mastocytosis - A disease of the hematopoietic stem cell. Dtsch Arztebl. 2008;105(40):686-692. doi:10.3238/arztebl.2008.0686

11. Pardanani A, Tefferi A. Systemic mastocytosis in adults: A review on prognosis and treatment based on 342 Mayo Clinic patients and current literature. Curr Opin Hematol. 2010;17(2):125-132. doi:10.1097/MOH.0b013e3283366c59

12. Czarny J, Lange M, Ługowska-Umer H, Nowicki RJ. Cutaneous mastocytosis treatment: Strategies, limitations and perspectives. Postep Dermatologii i Alergol. 2018;35(6):541-545. doi:10.5114/ada.2018.77605

13. Solis U, Luis J, González V, Geovanny B, Cajo H. Manifestaciones óseas de la mastocitosis cutánea. Presentación de un caso. Rev Colomb Reumatol. 2016;3(4):266-270.

14. Hernández EM, Olguín PO, Sánchez ÁMR, Gómez AV. Mastocytic lentiginous pigmentation. Med Cutan Ibero Lat Am. 2020;48(1):80-84. doi:10.35366/93983

15. Suso L, Merino A, Parra V, Innocenti C. MASTOCITOSIS CUTÁNEAS A PROPÓITO DE TRES CASOS DE URTICARIA PIGMENTOSA. Rev MÉDICA Univ - Fac Ciencias Médicas -UNCuyo. 2015;11(1):1-6.

16. Dumas L, Peroni D, Maino O, Acuña C, Tubio R. Mastocitosis Cutánea En Niños: Reporte De 23 Casos En 5 Años. Rev argentina dermatología. 2019;100(2):41-50.

17. Ávila JA, Cala JC, Gelvis JA. Urticaria Pigmentosa in Adults. Med UNAB. 2012;15(1):63-67. doi:10.1111/j.1365-2133.1925.tb09214.x 
18. Desmond DH, Carmichael MG. Systemic Mastocytosis: The Difficult Patient with a Rare Disease. Case Presentation and Brief Review. Hawaii J Med Public Health. 2018;77(2):27-29.

http://www.ncbi.nlm.nih.gov/pubmed/29435387\%0Ahttp://www.pubmedcentral.nih.gov/articlerender.fcgi? artid=PMC5801525

19. Matito A, Álvarez-Twose I, Morgado JM, Sánchez-Muñoz L, Orfao A, Escribano L. Clinical impact of pregnancy in mastocytosis: A study of the Spanish network on mastocytosis (REMA) in 45 cases. Int Arch Allergy Immunol. 2011;156(1):104-111. doi:10.1159/000321954

20. Hartmann K, Escribano L, Grattan C, et al. Cutaneous manifestations in patients with mastocytosis: Consensus report of the European Competence Network on Mastocytosis; The American Academy of Allergy, Asthma \& Immunology; And the European Academy of Allergology and Clinical Immunology. $J$ Allergy Clin Immunol. 2016;137(1):35-45. doi:10.1016/j.jaci.2015.08.034

21. Vikse J, Omdal R. Fatigue in Mastocytosis: A Case Series. Clin Ther. 2019;41(4):625-632. doi:10.1016/j.clinthera.2019.01.016

22. Bhullar H, Saracino A, Douglass J, Varigos G, Nicholls K, Martyres R. Mastocytosis: A case series of 107 consecutive patients. Br J Dermatol. 2018;178(1):28-29. doi:10.1111/ijlh.12426

23. Schwartz LB, Irani AMA. Serum tryptase and the laboratory diagnosis of systemic mastocytosis. Hematol Oncol Clin North Am. 2000;14(3):641-657. doi:10.1016/S0889-8588(05)70300-2

24. Heide R, Van Doorn K, Mulder PG, et al. Serum tryptase and SCORMA (SCORing MAstocytosis) Index as disease severity parameters in childhood and adult cutaneous mastocytosis. Clin Exp Dermatol. 2009;34(4):462-468. doi:10.1111/j.1365-2230.2008.03005.x

25. Sperr WR, Jordan JH, Fiegl M, et al. Serum tryptase levels in patients with mastocytosis: Correlation with mast cell burden and implication for defining the category of disease. Int Arch Allergy Immunol. 2002;128(2):136-141. doi:10.1159/000059404

26. Lange M, Niedoszytko M, Nedoszytko B, Łata J, Trzeciak M, Biernat W. Diffuse cutaneous mastocytosis: Analysis of 10 cases and a brief review of the literature. J Eur Acad Dermatology Venereol. 2012;26(12):1565-1571. doi:10.1111/j.1468-3083.2011.04350.x

27. Leder K, Weller PF. Eosinophilia and helminthic infections. Bailliere's Best Pract Res Clin Haematol. 2000;13(2):301-317. doi:10.1053/beha.1999.0074

28. Pardanani A, Lim KH, Lasho TL, et al. Prognostically relevant breakdown of 123 patients with systemic mastocytosis associated with other myeloid malignancies. Blood. 2009;114(18):3769-3772. doi:10.1182/blood-2009-05-220145

29. Valent P, Akin C, Sperr WR, et al. Mastocytosis: Pathology, genetics, and current options for therapy. Leuk Lymphoma. 2005;46(1):35-48. doi:10.1080/10428190400010775

30. Siebenhaar F, Akin C, Bindslev-Jensen C, Maurer M, Broesby-Olsen S. Treatment strategies in mastocytosis. Immunol Allergy Clin North Am. 2014;34(2):433-447. doi:10.1016/j.iac.2014.01.012

31. Mimiola E, Bomben R, De Matteis G, et al. Systemic mastocytosis associated with myelodysplastic/myeloproliferative neoplasms with ring sideroblasts and thrombocytosis: Report of three cases. Hematol Oncol. 2019;37(5):628-633. doi:10.1002/hon.2680

32. Hadzijusufovic E, Peter B, Gleixner K V., et al. H1-receptor antagonists terfenadine and loratadine inhibit spontaneous growth of neoplastic mast cells. Exp Hematol. 2010;38(10):896-907. 
doi:10.1016/j.exphem.2010.05.008

33. Arock M, Akin C, Hermine O, Valent P. Current treatment options in patients with mastocytosis: Status in 2015 and future perspectives. Eur J Haematol. 2015;94(6):474-490. doi:10.1111/ejh.12544

34. Alvarez-twose I, Matito A, Morgado JM, et al. Imatinib in systemic mastocytosis: a phase IV clinical trial in patients lacking exon 17 KIT mutations and review of the literature. 2016;8(40):68950-68963.

\section{Table 1}

DESCRIPTION OF SOCIODEMOGRAPHIC, CLINICAL AND PARACLINICAL VARIABLES:

\section{Table 1.}

Demographic, clinical, laboratory and management characteristics. 
Table 1. Demographic, clinical, laboratory and management characteristics.

\begin{tabular}{|c|c|c|c|}
\hline \multirow[t]{2}{*}{ Variables } & \multirow{2}{*}{$\begin{array}{l}\text { Number of patients } \\
(\%)\end{array}$} & \multicolumn{2}{|l|}{ Diagnosis } \\
\hline & & $\begin{array}{l}\text { Cutaneous } \\
\text { Mastocytosis }\end{array}$ & $\begin{array}{l}\text { Systemic } \\
\text { Mastocytosis }\end{array}$ \\
\hline $\begin{array}{l}\text { Number of patients with } \\
\text { mastocytosis }\end{array}$ & 7 & 4 & 3 \\
\hline
\end{tabular}

\section{Diagnosis}

Skin biopsy $\quad 4(57 \%)$

Bone marrow biopsy $\quad 3(43 \%)$

Gender

$\begin{array}{llll}\text { Male } & 2(28 \%) & 2(100 \%) & 0(0 \%) \\ \text { Female } & 5(71 \%) & 2(40 \%) & 3(60 \%)\end{array}$

\section{Hallazgos clínicos}

\section{Clinical findings}

$\begin{array}{llll}\text { Pruritus } & 4(57 \%) & 3(75 \%) & 1(33 \%) \\ \text { Diarrhea } & 2(28 \%) & 0(0 \%) & 2(67 \%) \\ \text { Headache } & 2(28 \%) & 1(25 \%) & 1(33 \%) \\ \text { Insomnia } & 1(14 \%) & 0(0 \%) & 1(33 \%) \\ \text { Epistaxis } & 1(14 \%) & 1(25 \%) & 0(0 \%) \\ \text { Abdominal pain } & 1(14 \%) & 1(25 \%) & 0(0 \%)\end{array}$

\section{Signs}

Skin lesions

Darier's sign

\section{Laboratories}

Serum tryptase $>20 \mathrm{ng} / \mathrm{ml}$

C-KIT mutation

Hemogram

Leukocytes

Neutrophils

Lymphocytes

Eosinophils

Monocytes
$7(100 \%)$

1 (14\%)

$2(28 \%)$

$1(14 \%)$

Average: 7922

Average: 3820

Average: 1945

Average: 1112

Average: 314
$4(100 \%)$
$3(100 \%)$

1 (25\%)

$0(0 \%)$

$\begin{array}{ll}0(0 \%) & 2(67 \%) \\ 1(25 \%) & 0(0 \%)\end{array}$




\begin{tabular}{|c|c|c|c|}
\hline Serum Tryptase & \multicolumn{3}{|c|}{ Average: 29} \\
\hline LDH & \multicolumn{3}{|c|}{ Average: 443} \\
\hline Ferritin & \multicolumn{3}{|c|}{ Average: 205} \\
\hline \multicolumn{4}{|c|}{ Pharmacologic Management } \\
\hline Antihistamines & $6(86 \%)$ & $3(75 \%)$ & $3(100 \%)$ \\
\hline Ranitidine & $1(14 \%)$ & $1(25 \%)$ & $0(0 \%)$ \\
\hline Corticosteroids & $3(43 \%)$ & $2(50 \%)$ & $1(33 \%)$ \\
\hline $\begin{array}{l}\text { Anti-leukotrienes } \\
\text { (Montelukast) }\end{array}$ & $1(14 \%)$ & $0(0 \%)$ & $1(33 \%)$ \\
\hline Imatinib & $1(14 \%)$ & $0(0 \%)$ & $1(33 \%)$ \\
\hline
\end{tabular}

\section{Figures}

\section{Distribution of Patients by Age (years)}

$60 \%$

$50 \%$

$50 \%$

$40 \%$

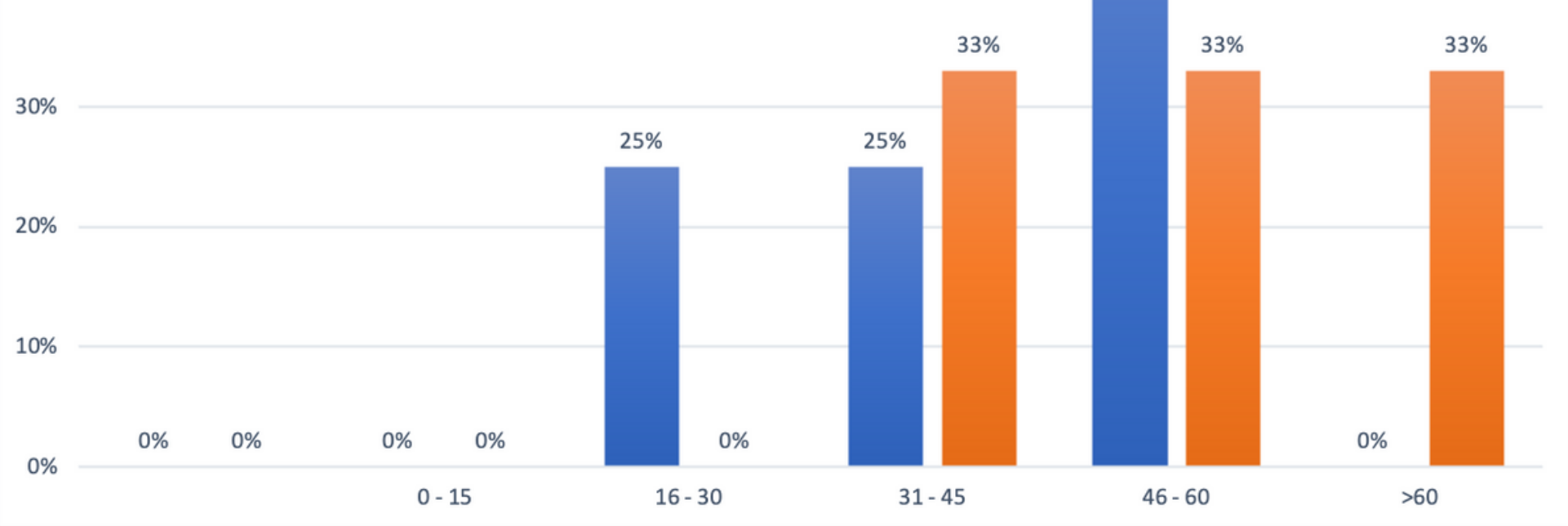

Figure 1

Graph 1: no caption available with this version. 


\section{Distributed by sex according to Type of Mastocytosis}

\section{$120 \%$}

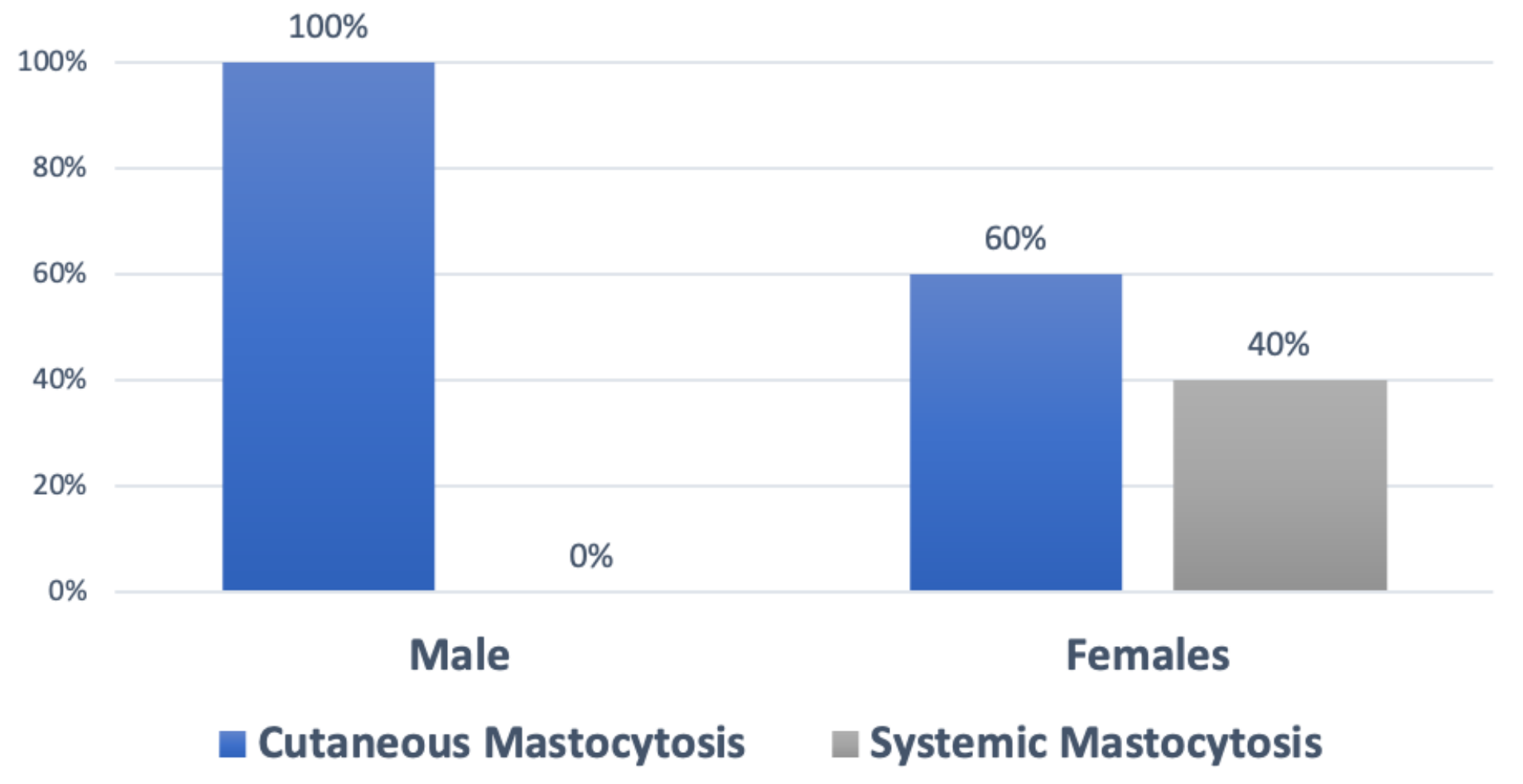

Figure 2

Graph 2: no caption available with this version. 


\section{Symptoms according to type of Mastocytosis}

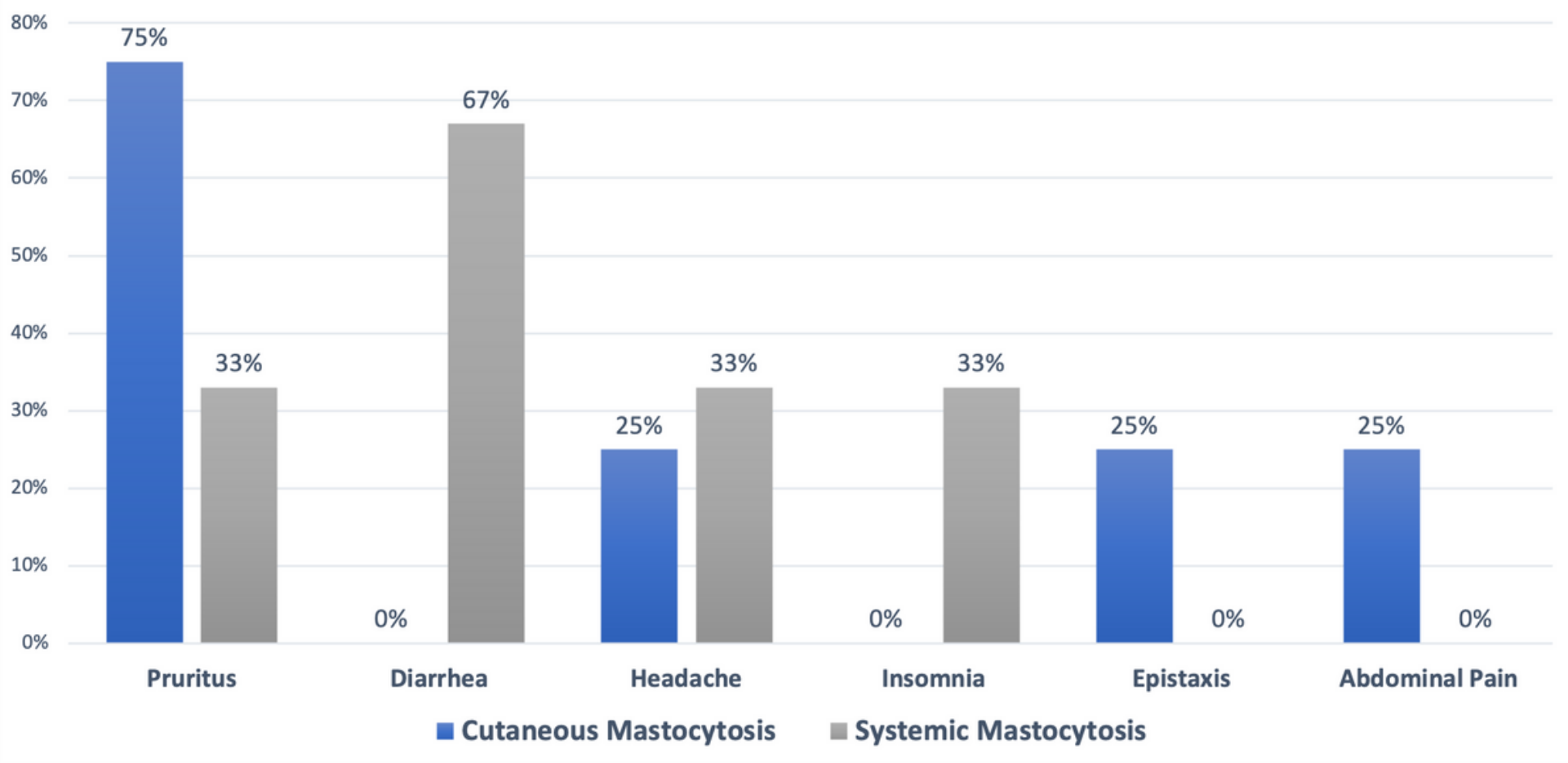

Figure 3

Graph 3: no caption available with this version.

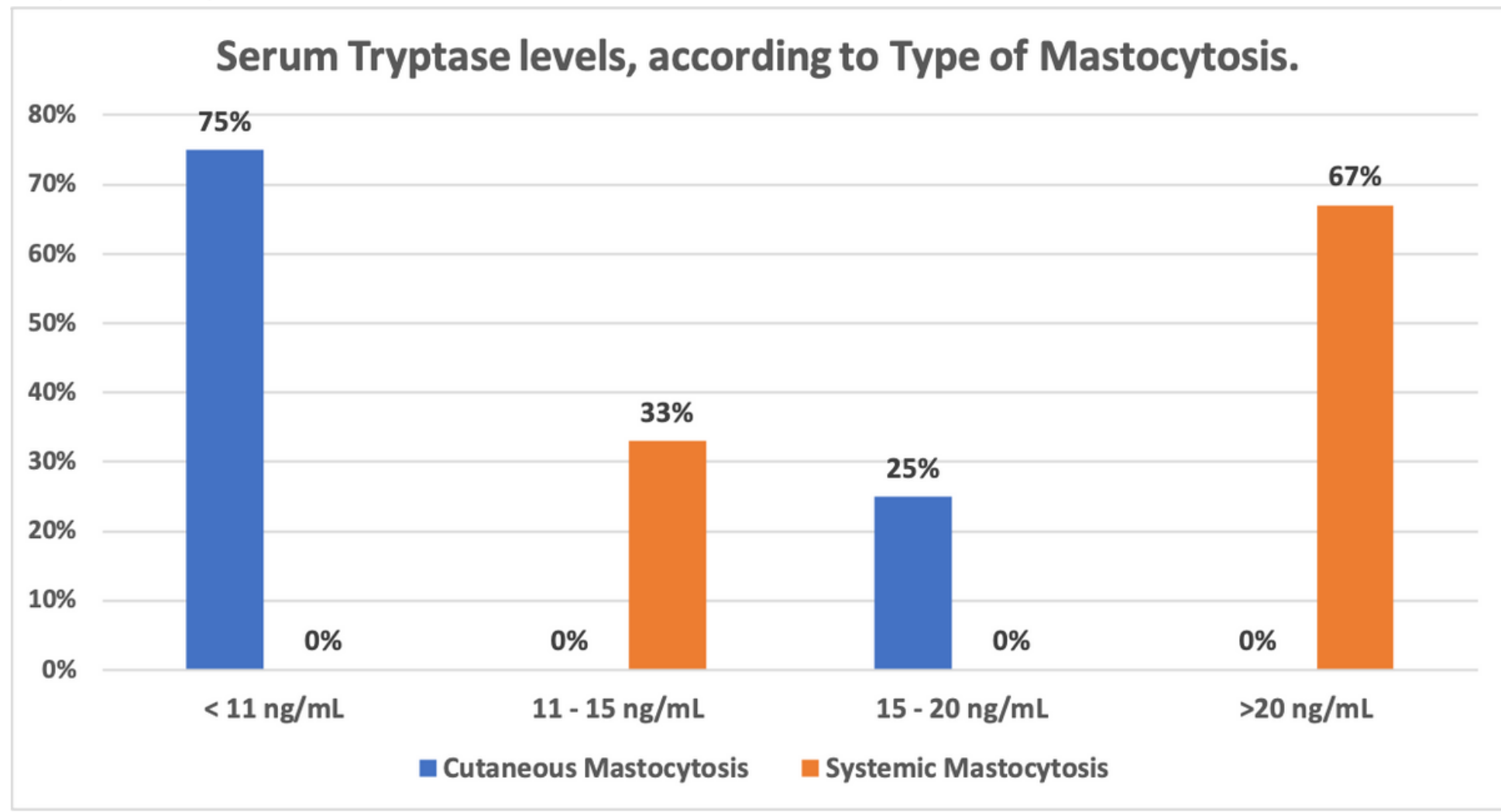

\section{Figure 4}

Graph 4: no caption available with this version. 


\section{Treatment received, according to Type of Mastocytosis}

$120 \%$

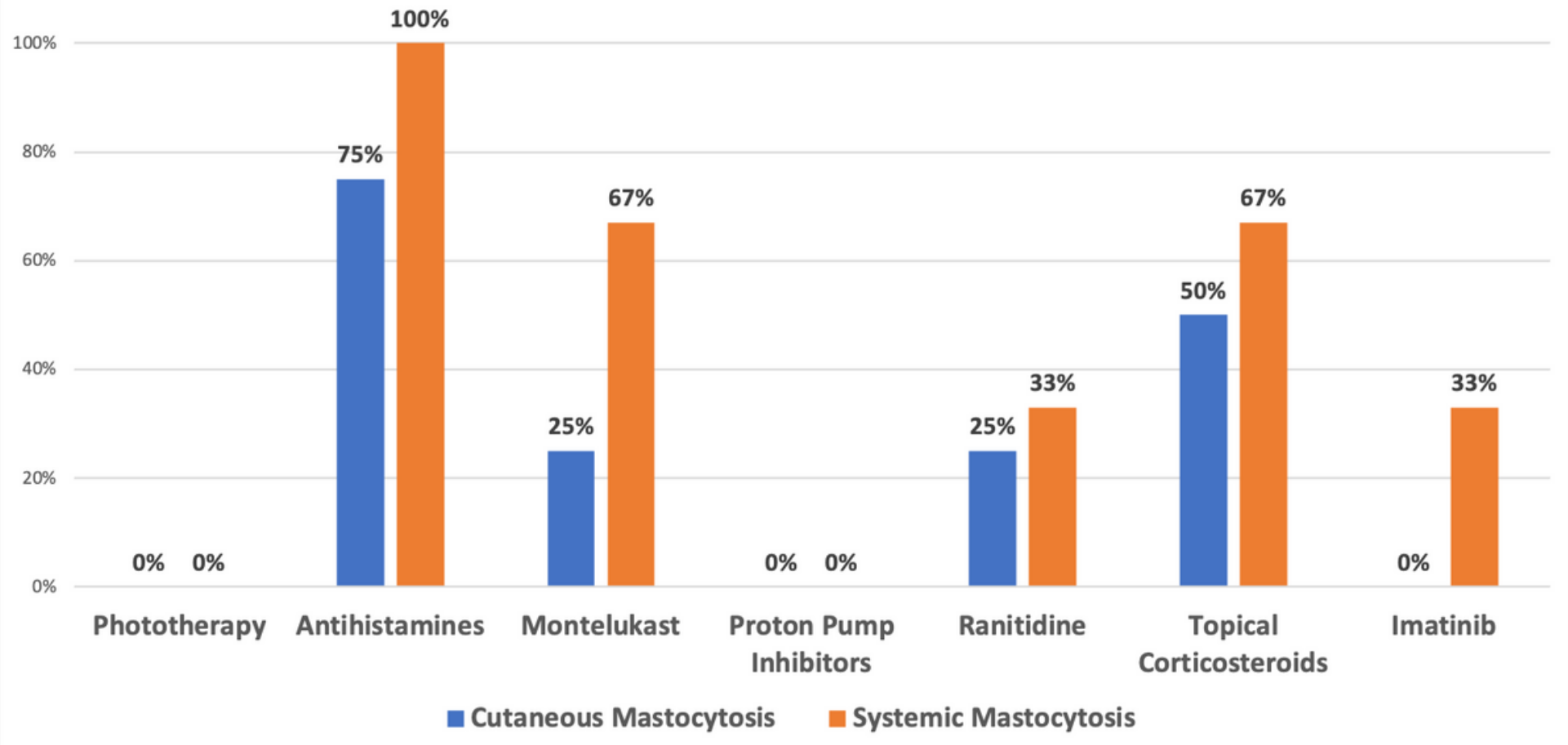

Figure 5

Graph 5: no caption available with this version.

\section{RESPONSE TO TREATMENTS RECEIVED}

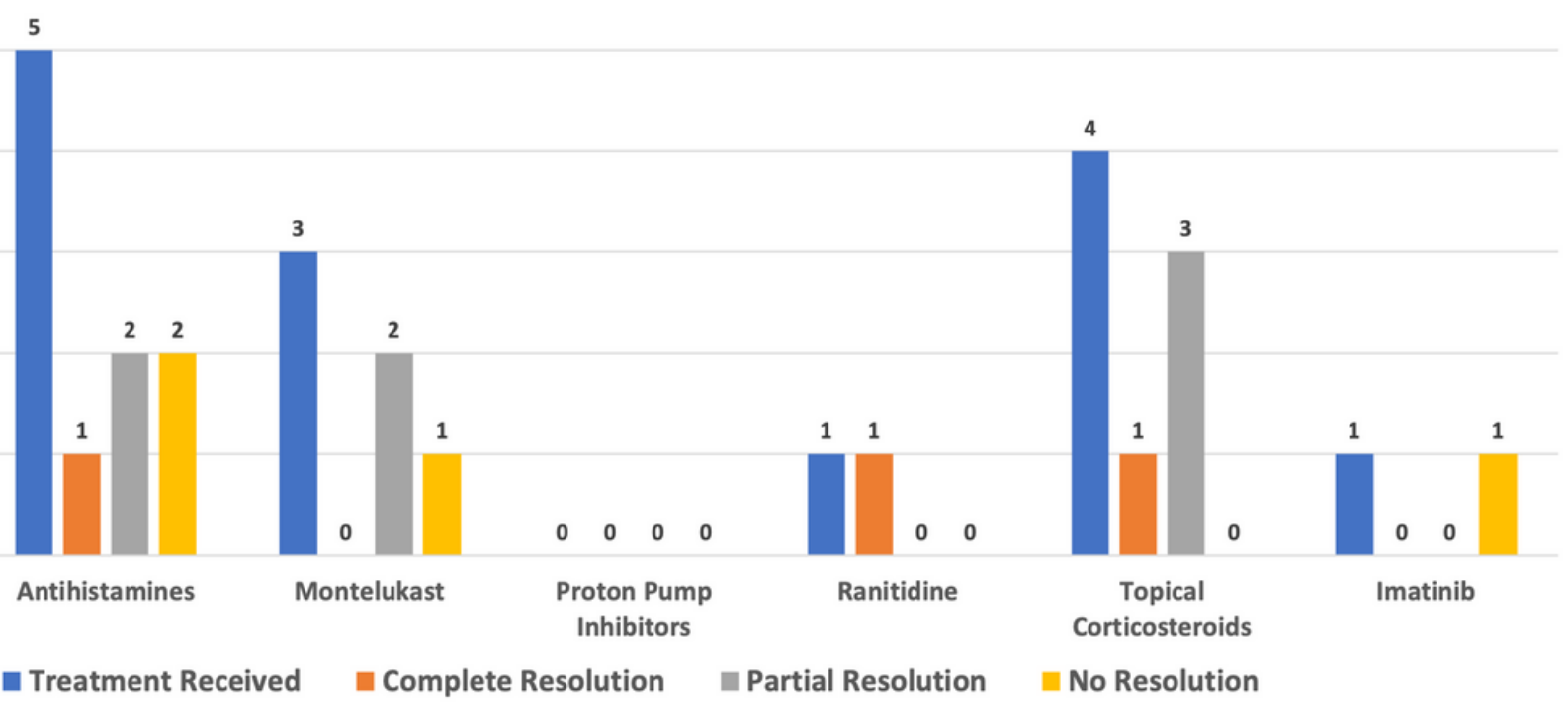

Figure 6

Graph 6: no caption available with this version. 